\title{
Teaching Students Problem Solving in Introductory Physics - Forming an Initial Hypothesis of Instructors' Beliefs
}

\author{
Vince H. Kuo*, Kenneth Heller*, Patricia Heller*, Charles Henderson ${ }^{+}$, Edit Yerushalmi ${ }^{\xi}$ \\ *Physics Education Research Group, University of Minnesota, Minneapolis, MN \\ ${ }^{+}$Western Michigan University, Kalamazoo, MI \\ ${ }^{\xi}$ Weizmann Institute, Rehovot, Israel
}

This paper presents an initial hypothesis of instructors' beliefs about their role in helping students learn to solve problems in an introductory calculus-based physics course. Instructors see their teaching role as primarily providing resources and making suggestions, with little mentioning of how they influence the students to use the resources or follow the suggestions.

\section{Introduction}

The previous paper [1] described the development of an initial hypothesis of physics instructors' views of the students' role in learning problem solving in an introductory physics course. Here we focus on how these instructors think about their role in this process. This part of the hypothesis shows that instructors see their teaching role primarily as managing the students' engagement in learning activities. [2] Not surprisingly, the instructors described three distinct ways that they manage student learning: (1) Providing Resources; (2) Making Suggestions; and (3) Setting Constraints.

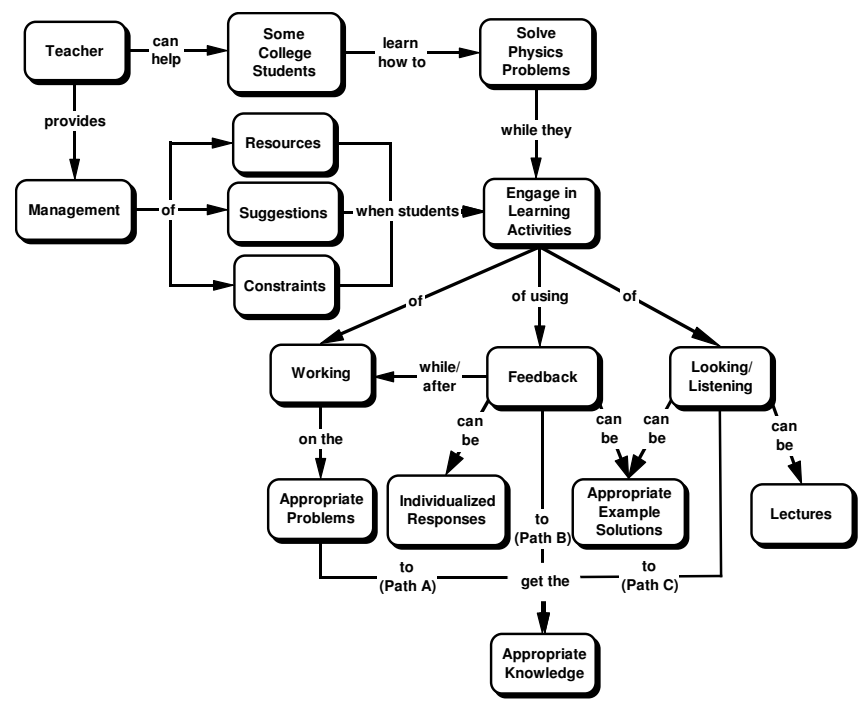

\section{Connections to Learning Activities}

The first paper [1] described three independent ways that instructors believe students are able to learn to solve physics problems: (1) Working on problems; (2) Using Feedback while/after working on problems; and (3) Looking/Listening to example problem solutions or lectures. Figure 1 shows that the instructors believe that all of the three ways of management can be used to determine how students engage in these learning activities.

Two interesting features came from a comparison between how these instructors view their teaching and how they believe students learn. First, the instructors seemed most concerned with managing the feedback that students receive. They believed that learning takes place directly from feedback. Nevertheless, a separate background questionnaire shows that these

Figure 1: Highest-level concept map describing an initial hypothesis of instructor's conceptions about the teaching and learning of problem solving.

instructors do not spend significantly more time preparing feedback than any other teaching activity. Second, the instructors viewed their teaching as a passive management of students' engagement in learning activities, with their primary functions as providing resources and making suggestions. On the other hand, they did not believe that most students properly use these resources or take the suggestions. Nevertheless, these instructors did not consider actively influencing student behavior by modifying their grading. These and other findings are discussed briefly below. 


\section{Management of Students' Learning}

\section{A. Working on Problems}

In this mode instructors manage student work by providing problems. In some cases the instructors suggested that students work on problems (e.g., un-graded homework). In other cases, the instructors required students to work on the problems (e.g., tests).

Providing Resources: All of the instructors described choosing appropriate problems that encourage students to do things that will help them learn while working on problems. These instructors believed that useful problems had at least some of the following attributes: (i) requires consideration of the physical principles behind the problem; (ii) conveys the message that physics is related to reality by posing problems in realistic or semirealistic situations; and (iii) is based on the current state of the students' knowledge.

Making Suggestions: Half of the instructors described their role as primarily making suggestions that students practice working on a lot of appropriate problems. A few of the instructors also believed that they should suggest particular techniques to enhance student learning. An example of such suggestions was that students should first guess the answer to the problem, and after working through the problem, compare their guess to the calculated answer. Although pressed, there was no indication in the interviews of why they believe these suggested techniques enhance students' learning.

Setting Constraints: Although instructors believed that students should practice working on problems, only a minority of the instructors believed in forcing students to do so on their own by, for example, grading their solutions. One instructor saw tests as the only situation in which students worked seriously on a problem without prematurely looking for help. Most instructors, however, did not view the act of taking tests themselves to be beneficial to learning. Rather, they believe that students can learn from the feedback that they receive after taking the test.

\section{B. Using Feedback}

The instructors believed that useful feedback could occur while the student is solving a problem (i.e., coaching), or after the student has solved

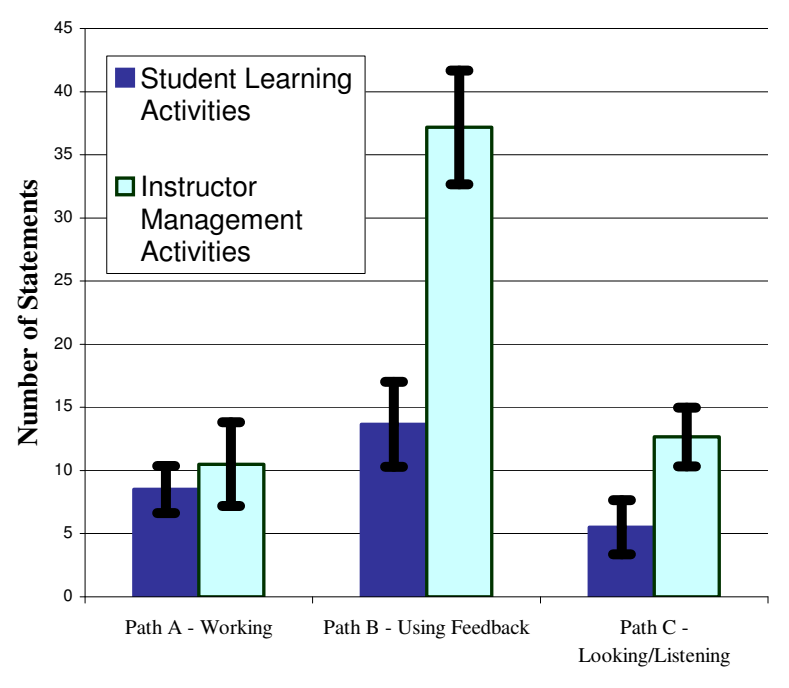

Figure 2: Average number of statements made by the instructors during the interview about each of the three paths of learning. The error bars are the standard error calculated for the average of the 6 instructors.

a problem (e.g., providing example problem solutions or giving grades). Indeed, the instructors talked about their management of this type of instruction much more than any other teaching or learning activity (see Figure 2). However, there was no indication of whether the instructors believe that one form of feedback is better than the other, or even if they are qualitatively different.

All of these instructors believed students could learn if provided feedback, and they believed how students used that feedback was important. They also believed that most students did not use the feedback appropriately. However, they did not have a belief that the instructor should actively influence feedback usage.

Providing Resources: The instructors believed that resources for feedback came in three forms: (i) Written example problem solutions; (ii) Personal coaching; and (iii) Test grades. When considering what should be included in an example problem solution, these instructors expressed conflicting values. They believed that example solutions should be detailed enough to provide necessary feedback but that such detailed solutions pose barriers to the already less than motivated students (i.e., they thought students would be less likely to read a detailed solution). [3] 
Some of the instructors also expressed the value of providing feedback while students were working on problems. Here the instructor provides feedback via management of peer coaching (by setting up small groups) or by direct instructor coaching (by being available during office hours). Some of them believed peer coaching was almost as helpful as their personal coaching, and required considerably less instructor time.

Grading was considered to be the feedback mechanism for students on tests. The instructors believed that grading problems on tests could influence students to exhibit desirable behavior in subsequent tests. However, the manner in which they grade are often counter to the values that instructors wish to communicate. [4]

Making Suggestions: Half of the instructors described suggesting to students that they come to office hours for individual coaching if they were having difficulties in the class. This coaching would take the form of providing feedback as the student tries to solve a problem. These instructors place a very high value on their coaching in office hours, even though in questionnaires faculty office hours were rated by students as one of the least valuable resources available in the course. The primary mode by which instructors believed they could facilitate feedback was by suggesting that students first work on problems and then come to their office hours, even though the instructors realize that very few students do this.

\section{Looking and Listening}

The instructors only described teaching activities of providing resources in this context. They did not have any belief that they should either suggest how students should use this information or influence students to use the information.

Providing Resources: All of the instructors believed that their solving problems during lecture conveyed useful information to students. For example, one instructor stated, "I can simply tell students ... that Bernoulli's equation has three terms in it, and you could have two kind of problems." [2] Some of the instructors also believed that lecturing to students about specific problem-solving techniques was beneficial.

A few instructors believed that presenting interesting example problems in lecture developed student interest so that students are motivated to understand the material.

\section{Discussion}

To be of general use, the hypothesis should, and will be tested using a broader sample of instructors. The hypothesis presented in this paper is that instructors believe teaching consists of managing the three distinct modes by which students learn to solve physics problems. They believe that some students can learn to solve physics problems through any one of these activities. All of the instructors spent considerably more time during the interview discussing the management of feedback to the students. However, this is not representative of the reported time spent preparing or performing various teaching activities. If this apparent conflict between values (providing feedback as most important) and time (various teaching activities are equally prominent) is found for instructors in general, it may provide a way for curriculum developers to encourage instructors to consider alternative instructional approaches by highlighting this conflict. [5] For example, modern advances in technology may provide class response systems that provide individualized problemsolving feedback to students interspersed during the lecture [6] without taking significant amounts of time away from various other teaching activities. This would allow instructors to be more active in providing individualized feedback.

Another feature of these instructors' view of managing students' learning activities with respect to feedback is that they primarily describe their role as passive, making suggestions and providing resources. Instructors appear to believe that they often cannot or should not directly coerce students (by grading practices) to engage in activities that the instructors believe is beneficial. They expect students to take responsibility for their own learning while recognizing that they do not do so. Since these instructors appear to lack an explicit knowledge of mechanisms by which students learn, [2] they may not know what actions they should require of the students. For example, instructors may not know what they could, or should, require students to do with written solutions that they provide. 
Since many of the available curricular material are designed to promote problem solving by providing students with a concrete problem-solving framework, [7 - 11] it is important to know how instructors perceive these constraints. If they are opposed, in principle, to requiring specified learning activities, these approaches might be revised to soften the importance of the scaffolding. Alternatively, if the instructors lack specific knowledge to appreciate the value of constraining students' practices to facilitate learning, appropriate professional development might be designed to make this type of material more acceptable.

${ }^{1}$ Henderson, C., Heller, K., Heller, P., Kuo, V.H., \& Yerushalmi, E., How Students Learn ProblemSolving - Forming An Initial Hypothesis of Instructors' Beliefs, Proceedings of the Physics Education Research Conference, Boise, ID. August, 2002.

${ }^{2}$ Henderson, C., Faculty Conceptions about the Teaching and Learning of Problem Solving in Introductory Calculus-Based Physics. Unpublished Doctoral Dissertation, University of Minnesota, 2002 (online at: http://homepages.wmich.edu/ chenders).

${ }^{3}$ For more discussion, see Henderson, C., Heller, K., Heller, P., Kuo, V.H., \& Yerushalmi, E., Instructors' Beliefs about Teaching using Example Problem Solutions, Presentation at AAPT Winter Conference, Philadelphia, PA. January, 2002 (online at: http://www.physics.umn.edu/groups/physed/ Talks/ talks.html).

${ }^{4}$ For more details about grading, see: Kuo, V.H., Heller, K., Heller, P., Henderson, C., \& Yerushalmi, E., Instructors' Ideas about Problem Solving - Grading, Proceedings of the Physics Education Research Conference, Rochester, NY. July, 2001.

5 It has been shown that students can be encouraged to change their conceptions about physical phenomena by exposing conflicts within their belief system. See, for example: Posner, G.J., Strike, K.A., Hewson, P.W., \& Gertzog, W.A., Accommodation of a scientific conception:
Toward a theory of conceptual change, Science Education, vol. 66:2, pp. 211-227, 1982.

${ }^{6}$ McKeachie, J.W., Teaching tips: strategies, research, and theory for college and university teachers. Lexington, MA: D.C. Heath. 1994.

${ }^{7}$ Heller, P., Keith, R., \& Anderson, S., Teaching problem solving through cooperative grouping. Part I: Groups versus individual problem solving, American Journal of Physics, vol. 60, pp. 627-636, 1992.

${ }^{8}$ Heller, P., \& Hollabaugh, M., Teaching problem solving through cooperative grouping. Part II: Designing problems and structuring groups, American Journal of Physics, vol. 60, pp. 637-644, 1992.

${ }^{9}$ Leonard, W., Dufresne, R., \& Mestre, J., Using qualitative problem-solving strategies to highlight the role of conceptual knowledge in solving problems, American Journal of Physics, vol. 64, pp. 1495-1503, 1996.

${ }_{10}$ Reif, F., \& Scott, L. A., Teaching scientific thinking skills: Students and computers coaching each other, American Journal of Physics, vol. 67, pp. 819-831, 1999.

${ }_{11}$ Van Heuvelen, A., Leraning to think like a physicist: A review of research-based instructional strategies, American Journal of Physics, vol. 59, pp. 891-897, 1991. 